\title{
Impact of Microwave Disinfestation Treatments on the Bacterial Communities of No-till Agricultural Soils
}

\author{
M. J. KHAN ${ }^{\text {a }}$, S. JURBURG ${ }^{\text {b }}$, J. HE ${ }^{\text {a }}$, G. BRODIE ${ }^{a}$ AND D. GUPTA ${ }^{\text {a }}$ \\ ${ }^{a}$ School of Agriculture and Food, Faculty of Veterinary and Agricultural Sciences, The \\ University of Melbourne, Victoria, 3010, Australia \\ ${ }^{\mathrm{b}}$ German Centre for Integrative Biodiversity Research (iDiv), Halle-Jena-Leipzig, \\ Germany
}

*Corresponding Author: Muhammad Jamal Khan

E-mail: mkhan3@student.unimelb.edu.au

Running Title: Microwave soil heating alters soil bacterial communities

This is the author manuscript accepted for publication and has undergone full peer review but has not been through the copyediting, typesetting, pagination and proofreading process, which may lead to differences between this version and the Version of Record. Please cite this article as doi: $10.1111 /$ ejss. 12867

This article is protected by copyright. All rights reserved. 


\section{Summary}

Growing herbicide resistance has encouraged the development of new technologies for weed control. Pre-sowing microwave (MW) soil heating has been shown to reduce weed establishment in no-till farming systems, and substantially increases crop productivity. However, the effect of this technology on the soil microbial community in general, and on beneficial soil microbes such as ammonia oxidizers in particular, warrants further study. In order to check the effect of MW soil disinfestation treatment on the soil biota, indigenous soil microcosms were treated under a horn antenna of the MW prototype for three distinct durations. Immediately after heating (T0) and 28 days after heating (T28), the soil was collected at two penetration depths ( $0-5$ and $5-10$ $\mathrm{cm}$ ) of MW energy to determine the bacterial community responses based on the $16 \mathrm{~S}$ rRNA amplicon sequencing and the total abundance of bacteria and ammonia oxidisers with qPCR. While total bacteria and ammonia oxidizers exhibited no response to the MW treatments, bacterial community composition differed according to the treatment durations. Community responses clustered into two categories: no effect at low heating intensities ( 0 and $30 \mathrm{~s}, 17-45^{\circ} \mathrm{C}$ ); and strong effect at high heating intensities (60 and $\left.90 \mathrm{~s}, 65-78^{\circ} \mathrm{C}\right)$. For the latter group, community richness did not recover to its preheating levels within the four weeks studied. Immediately after high heating intensities treatments, the relative abundance of Firmicutes increased, and that of Proteobacteria decreased significantly regardless of penetration depth. The relative abundances of beneficial soil microbes (Micromonosporaceae, Kaistobacter and Bacillus) were significantly higher as soils recovered from high heating intensities compared with 
untreated soils at T28. Our findings suggest that while pre-sowing MW treatments alter the soil microbial community, beneficial soil microbes exhibit faster recovery. Keywords: microwave weed management, soil heating, soil bacteria, microbial recovery, heat resistant.

\section{Highlights}

1. High heating intensities significantly reduced the bacterial community richness and community did not recover to its pre-heating condition within the studied time. 2. Heat resistant bacterial taxa survived the high heating intensities proposed for sterilizing weed seedbank, exhibited recovery and remained dominant in the community over 28 days after heating regardless of penetration depth.

3. High heating intensities did not induce a negative impact on the abundance of ammonia-oxidizing bacteria and archaea.

4. Overall, microwave soil heating altered the bacterial community and dormant heat-resistant taxa benefited and exhibited recovery.

\section{Introduction}

Agricultural pests are enormously declining the sustainability of farmland (Fischer \& Connor, 2018), and the traditional usage of chemicals for pest control has shifted the pests' adaptability to resist this widely adopted control measure. This adaptability of pest organisms (i.e., pesticides and herbicides resistance) can impose a significant challenge to sustainable food production. Therefore, modern agriculture systems require 
sustainable pest control practices to ensure food security (Pretty \& Bharucha, 2014). Among these practices, the development and adoption of non-chemical weed control techniques is one of the most pressing areas in need of development, due to the evolution of herbicide-resistant weeds (Heap, 2016), chemical residues in food chain (Fritschi et al., 2015; Cozma et al., 2017) and deterioration of the cropping environment (Fischer \& Connor, 2018). Therefore, an alternative approach in farming system is needed to cope with pests’ adaptability.

Microwave (MW) soil heating for weed management has been proposed as an alternative to chemicals in the agriculture industry (Nelson, 1996; Sartorato et al., 2006; Brodie et al., 2009; Khan et al., 2017). MW is a part of electromagnetic spectrum within a frequency range of $300 \mathrm{MHz}<f<300 \mathrm{GHz}$ (Banik et al., 2003). The heating process relies on the partial and/or complete dissipation of the MW electromagnetic field into the load, which ultimately induces polarization of dipolar molecules (i.e., water), resulting in the rapid increase in the temperature of the dielectric material due to internal resistance (Metaxas \& Meredith, 1983; Diprose et al., 1984). In the case of a pre-emergence weed management, this rapidly increased temperature devitalises the weed seedbank by generating micro-steam explosions in the seeds, leading to their mortality in the top soil horizons and thus preventing the emergence of weeds (Khan et al., 2017; Khan et al., 2018). This characteristic, real time heating, of MW technology distinguishes it from the numerous classical thermal methodologies, for example: soil steaming and soil solarization, for weed and pathogen control (Brodie, 2018). 
We have previously designed and developed a prototype to harness this property of MW energy by irradiating agricultural fields between crop rows for weed management (Brodie et al., 2018). This prototype has been successfully employed to minimize the regeneration capacity of the soil weed seedbanks up to certain depths into soils. Recently, numerous field trials demonstrated that pre-sowing MW soil heating (75 - 80 ${ }^{\circ} \mathrm{C}$; in top $0-8 \mathrm{~cm}$ ) significantly reduced weed emergence (Khan et al., 2017; Brodie et al., 2018; Khan et al., 2018). As this technology is in its pre-commercialization phase, the farming practitioners and policy makers are keen to know the response (i.e., recovery and/or reshaping after heat disturbance) of the soil microbial community, which is important to soil health and plant productivity (Berendsen et al., 2012), to MW energy along with the penetration depth into soil for disinfestation. Recently, Sabry et al. (2018) reported that a closed horn antenna, attached to a modified domestic MW (700W; 2.45GHz) system, reduced MW energy leakage and increased absorption. They found that penetration depth (up to $5 \mathrm{~cm}$ ) did not change the temperature intensity below the soil surface during the soil disinfestation process. But this is not always the case, numerous factors can cause temperature fluctuations below the soil surface. Given that, soil temperature fluctuation is entirely depended on the MW system and soils conditions, and this fluctuation causes reductions in the lethality of MW soil heating. Therefore, the variation in temperature distribution along the penetration depth may change the response of the soil microbial community and this response is unknown in terms of soil disinfestation achieve through this MW prototype. 
Soil is a complex heterogeneous environment (Lu et al., 2014), harboring a wealth of bacteria, fungi, protozoans, nematodes, and arthropods, which may be adversely affected by the MW soil treatment. Bacteria comprise the majority of the soil biota by biomass (Sánchez-Marañón et al., 2017). In general, soil heating creates a transient disturbance for soil bacterial communities, and may affect their composition and function (O'Brien et al., 2018). However, it is possible that the rapid growth and extreme diversity found in these communities results in a rapid recovery of both community structure and function, resulting in no long-term negative effects (Fierer, 2017). Nevertheless, it is likely that the long-term effects of heating depend on heating duration and intensity. For example, Nunes et al. (2018) evaluated the tolerance range of the soil bacterial community exposed to different MW heating durations and reported a 90\% reduction in total bacterial communities with 6.8 minutes of MW soil treatment. Additionally, they found communities' tolerance to MW to be phylogenetically constrained: Actinobacteria were highly susceptible to heating, Proteobacteria showed intermediate tolerance, and Firmicutes exhibited the highest resistance. Therefore, the heating duration decides the extent of soil sterilization and the behavior of surviving species, as observed by Nunes et al. (2018). The majority of previous studies employed a domestic MW oven (closed cavity) for soil treatment to check the bacterial community responses; however, the MW prototype channels MW energy via an openstructured horn antenna. This could vary the temperature distribution in soils. Therefore, bacterial community responses to short term temperature exposure, achieved through 
the MW prototype, is not well understood but is crucial for long-lasting productivity of soil systems after MW soil treatment for weed seedbank control.

In addition, the transient heat mediates the mineralization of organic nitrogen into ammonia $\left(\mathrm{HN}_{3}\right)$ (Zagal, 1989; Glass et al., 2008), and is subsequently converted to nitrate $\left(\mathrm{NO}_{3}^{-}\right)$via nitrification, which could enhance soil health for crop productivity. In soil, the conversion of ammonia to nitrite, an intermediate step in nitrification, is performed exclusively by two small, phylogenetically-conserved groups containing the ammonia monooxygenase $(a m o A)$ gene: ammonia oxidizing Archaea (AOA) and Bacteria (AOB; Banning et al., 2015). The tolerance range and rate of recovery of ammonia oxidizers to MW treatment is unknown but may be crucial to the maintenance of soil fertility following MW weed disinfestation. Previous studies have reported ammonia oxidizing microbes to be a slow-growing and sensitive functional group (Leininger et al., 2006; Banning et al., 2015), suggesting that they could indeed be negatively affected by the MW treatment.

In order to fully understand the potential effects of the MW weed disinfestation treatment and its role in shaping the soil microbiota, we exposed soil microcosms to the MW weed disinfestation treatments at three MW durations and monitored the bacterial community composition (16S rRNA amplicon sequencing and 16S rRNA qPCR) as well as the total abundances of AOA's and AOB's (qPCR). We sampled the microcosms immediately after treatment (T0) and 28 days later (T28). Because the treatments were expected to be more extreme on the upper soil strata, we separately 
sampled the soil at $5 \mathrm{~cm}$ and $10 \mathrm{~cm}$ to evaluate the effectiveness of the $\mathrm{MW}$ treatment in regard to penetration depth for disinfestation. We hypothesized that MW soil treatment would alter the bacterial community based on various taxa's temperature sensitivities and the damaged community would recover to its initial level within four weeks following the heat disturbance. Additionally, we hypothesized that the physiological adaptation of ammonia oxidisers to extreme events might help them to survive against this transient heat disturbance.

\section{Materials and Methods}

\section{Soil Collection and Microwave Heating:}

Soil was collected from a wheat paddock on temperate agricultural land at the Dookie Campus (36.395 ${ }^{\circ}$; $\left.145.703^{\circ} \mathrm{E}\right)$, of The University of Melbourne, Australia. This region is in the country's central grain growing belt, featuring a monocropping pattern with wheat-canola rotation, and is in the Goulburn Valley of North Victoria, Australia. The mean annual rainfall is $550 \mathrm{~mm}$ and mean annual temperature ranges from $9.4-20.9^{\circ} \mathrm{C}$ (Australian Bureau of Meteorology). The average load of inorganic nitrogen fertilizer for crop production in this region is $100-120 \mathrm{~kg} \mathrm{ha}^{-1}$ and herbicide application is the most common weed management practices.

Soil at the sampling site was a brownish grey loam and was classified as Red Mesotrophic-Haplic Dermosol according to Australian Soil Classification (Isbell, 2016), with a field capacity of $\simeq 53 \%$. Soils were collected with cores ( $2 \mathrm{~cm}$ diameter; $0-10$ cm depth), sieved (4-mm mesh size) and mixed thoroughly to produce a composite sample and shifted to the laboratory for microcosm establishment. Water content was 
measured by oven drying the soil at $105^{\circ} \mathrm{C}$ for $24 \mathrm{~h}$ and adjusted, with sterile distilled water, to $20 \%$ volumetric water content ( $\simeq 45 \%$ field capacity). Soil was placed in polyethylene plastic, transparent to MW energy, microcosms $(5 \times 5 \times 10 \mathrm{~cm})$ and preincubated at $25^{\circ} \mathrm{C}$ for three weeks in an incubator (Contherm Scientific Ltd.; Lower Hutt, New Zealand). To maintain the aerobic conditions, all the microcosms were aerated by opening lids every 3 days and moisture loss was replaced. Details of the soil properties are given in Table: S1 (Supplementary Material).

Microcosms were treated under one of the four open-structured horn antennas $(5.5 \times 11 \times 36 \mathrm{~cm})$ of a $2-\mathrm{kW}$ MW weed treatment system. This experimental system was designed to apply MW energy for pre- and post-emergence weed control between crop rows, with an inter-antennae distance of $19.5 \mathrm{~cm}$. It has four independently controlled 2kW MW generators, which are powered through two on-board 7 kVA 3-phase electrical generators (Figure S1; Brodie et al., 2017). Microcosms were subjected to three treatment durations (30, 60 and 90 s) as well as an untreated control conditions and sampled at two points following treatment ( 0 and 28 days), in quadruplicate. Irrespective of cropping systems, previous field trials have demonstrated that MW soil treatment for 60 and $90 \mathrm{~s}$ was enough to achieve the necessary temperature for killing weed seedbanks (75 - $80^{\circ} \mathrm{C}$; Brodie et al., 2018), and these durations were thus selected for further study. A 30 s duration was selected as an intermediate treatment. Thermal images were taken immediately ( $2-5$ s) after soil heating by using an infrared thermal camera (C2; FLIR Systems Inc.; Wilsonville, Oregon, USA). The raw images of each MW treatment were post-processed in the MATLAB ${ }^{\circledR}$ (The Mathworks Inc., 
Natick Massachusetts, USA) to evaluate the temperature distribution in the microcosm. At each sampling point, a small core $(1.5 \mathrm{~cm}$ in diameter) was collected at $0-5 \mathrm{~cm}$ and 5 - $10 \mathrm{~cm}$ depth from each replicate. For soil collection at T0, a small corer $(1.5 \mathrm{~cm}$ in diameter) was used to evacuate the soil column at each depth. Immediately after sampling, to avoid any disturbance in soil profile, the corer was positioned into the microcosm exactly where the sampling occurred until the final sampling happened at T28. This final sampling was done with a separate, but same sized, corer from both depths. The samples were immediately transfered to the laboratory and stored at - 20 ${ }^{\circ} \mathrm{C}$.

\section{DNA Extraction and qPCR:}

DNA was extracted from $0.25 \mathrm{~g}$ of soil with the Power Soil ${ }^{\mathrm{TM}}$ DNA Isolation Kit according to the manufacturer’s instructions (MoBio Laboratories Inc., Carlsbad, CA, USA). DNA extracts were quantified using a Nanodrop ${ }^{\mathrm{TM}}$ ND2000c spectrophotometer (NanoDrop Technologies, Wilmington, DE, USA), and their concentrations ranged between $20-80 \mathrm{ng} \mathrm{g}^{-1}$ soil.

qPCR was used to quantify the absolute abundances of archaeal and bacterial amoA genes, as well as the total bacterial abundances. All qPCR reactions were performed in a $\mathrm{CFX384}^{\mathrm{TM}}$ optical qPCR detection system (Bio-Rad, Laboratories Inc.; Hercules, CA, USA), and each sample was measured in triplicate. The reaction for quantification of the archaeal-amoA gene contained $10 \mu \mathrm{L}$ of SensiFAST (Bio-Rad Laboratories, USA), $1 \mu \mathrm{L}$ of each primer set in accordance with Francis et al. $(2005 ; 10 \mu \mathrm{M}$; Arch-amoAF and Arch-amoAR), $2 \mu \mathrm{L}$ of 10 -fold diluted DNA template and $6 \mu \mathrm{L}$ of water. Each 
bacterial-amoA qPCR reaction contained $10 \mu \mathrm{L}$ iTaq Universal SYBR GREEN Supermix (Bio-Rad Laboratories, USA), $1 \mu \mathrm{L}$ of each primer set according to Rotthauwe et al. (1997; $10 \mu \mathrm{M}$; amoA-1F and amoA-2R), $2 \mu \mathrm{L}$ of 10-fold diluted DNA template and $6 \mu \mathrm{L}$ of water. The thermal cycling conditions for both archaeal and bacterial $a m o A$ gene quantifications were as follows: $95^{\circ} \mathrm{C}$ for 3 min then 40 cycles of $95^{\circ} \mathrm{C}$ for $5 \mathrm{~s}, 60^{\circ} \mathrm{C}$ for $30 \mathrm{~s}$ and $72{ }^{\circ} \mathrm{C}$ for $45 \mathrm{~s}$. Standard curves, generated in each qPCR reaction by using plasmids, were linear over six orders of magnitude $\left(10^{4}-10^{9}\right.$ gene copies $\mu \mathrm{L}^{-1}$ ) with $\mathrm{r}^{2}$ values of $0.98-0.99$; efficiency was $85-100 \%$.

For the quantification of total bacteria, we quantified copies of $16 \mathrm{~S}$ rRNA. Each $20 \mu \mathrm{L}$ qPCR reaction consisted of $10 \mu \mathrm{L}$ iTaq Universal SYBR GREEN Supermix (Bio-Rad Laboratories, USA), $1 \mu \mathrm{L}$ of each primer set according to Suzuki et al. (2000; $10 \mu \mathrm{M}$; 1369F and 1492R), $2 \mu \mathrm{L}$ of 10 -fold diluted DNA template and $6 \mu \mathrm{L}$ of water. PCR thermal cycling conditions for $16 \mathrm{~S}$ rRNA gene amplification were as follows: $95^{\circ} \mathrm{C}$ for 10 min; followed by 40 cycles of denaturation at $95{ }^{\circ} \mathrm{C}$ for $15 \mathrm{~s}$, annealing at $54{ }^{\circ} \mathrm{C}$ for $30 \mathrm{~s}$, and extension at $72^{\circ} \mathrm{C}$ for $30 \mathrm{~s}$. Standard curves were generated for each qPCR reaction, which were linear over six orders of magnitude $\left(10^{4}-10^{9}\right.$ gene copies $\left.\mu \mathrm{L}^{-1}\right)$, with $r^{2}$ of $0.97-0.99$ and efficiency of $80-100 \%$.

\section{S rRNA Sequencing:}

16S rRNA amplicon sequences were used to estimate the relative abundances within the soil bacterial community. Two samples per condition were sequenced. The V3-V4 regions of the $16 \mathrm{~S}$ rRNA gene was amplified using primers $341 \mathrm{~F}$ and $806 \mathrm{R}$, as previously described (Yu et al., 2005). Paired-end sequencing was performed in an 
Illumina MiSeq sequencer (San Diego, CA, USA). Paired-end reads were merged with PEAR (v. 0.9.5; Zhang et al., 2013) and primers were trimmed. Reads were qualityfiltered, full-length duplicates were removed, and chimeras were filtered against the “rdp_gold” database using USEARCH (v. 8.0.1623; Edgar, 2010; Edgar et al., 2011) and UPARSE (Edgar et al., 2011). Singletons were removed. Reads were clustered at 97\% identity and assigned with the Greengenes database (Version 13_8, Aug 2013; DeSantis et al., 2006) in QIIME (v.1.8; Caporaso et al., 2010) 


\section{Statistical Analyses:}

All statistical analyses were performed in the R 3.4.0 software (Team, 2014) using the phyloseq (McMurdie \& Holmes, 2013) and vegan (Oksanen et al., 2008) packages.

Prior to the analysis of amplicon sequencing data, reads were randomly subsampled to 30, 745 reads for sample. The final dataset contained 6154 prokaryotic OTUs. Alpha diversity was evaluated using Shannon's diversity index, and differences between MW durations and sampling time (days after heating) were tested with a two-way ANOVA, and Tukey post-hoc test was performed to determine changes in response to soil heating intensities. Beta diversity was evaluated with a principal coordinate analysis (PCoA) of Bray-Curtis distances. Clustering patterns of the resulting ordination were assessed using adonis and betadisper from the vegan package. For genus-level analyses, taxa were agglomerated by genus, and individual ANOVAs for the effect of time and MW duration were performed for each genus. qPCR data was transformed to $\log _{10}$ prior to analyses. Differences between gene copy numbers for AOA, AOB, and total $16 \mathrm{~S}$ data were compared between treatments using ANOVA. Specific measurements are presented as mean \pm standard deviation. 


\section{Results}

\section{Temperature Distribution in Soil:}

The mean temperature of the untreated control soil was $20 \pm 2{ }^{\circ} \mathrm{C}$ (Figure $1 \mathrm{~A}$ ). Immediately after heating for 30, 60 and 90 s, soils exhibited sharp increases in temperature to $45.1 \pm 2.1,64.3 \pm 2.8$ and $78.3 \pm 2.1^{\circ} \mathrm{C}$, respectively, confirmed by infrared thermal images of the microcosm and liquid-in-glass thermometers (Figure 1B-D). The peak temperature for treatment duration was retained for less than $20 \mathrm{~s}$ in the soils following heat disturbance. A cross-sectional infrared thermal image of the microcosms indicated that the heating intensity gradually decreased along the penetration depth (Figure S4), and we categorized $0-5 \mathrm{~cm}$ depth as a high heating zone and $5-10 \mathrm{~cm}$ depth as a moderate heating zone based on temperature. Despite this, we detected a slightly higher reflection of MW energy in the moderate heating zone than in the high heating zone.

\section{Bacterial Community Composition:}

We performed 16S rRNA amplicon sequencing in order to observe the effect of MW heating on the bacterial community. A visual inspection of the PCoA of Bray-Curtis distances between samples, revealed clustering of samples exposed to 0 - $30 \mathrm{~s} \mathrm{MW}$, and samples exposed to 60 - 90 s MW (Figure 2). The first axis represented 53.6\% of the variation in community composition, and the second axis represented $13.8 \%$ of the variation. At T0, the soils exposed to $30 \mathrm{~s}$ MW heating clustered closely to control samples, regardless of penetration depths. A similar pattern was found at T28. In contrast, microcosms which were exposed to 60 - 90 s MW, clustered separately from 
the untreated controls soils and 30 s MW soil treatment. Therefore, we categorized these heating durations into two groups: low-intensity (0 - $30 \mathrm{~s})$ and high intensity (60 - $90 \mathrm{~s})$ treatments. Community composition significantly clustered according to these MW heating intensity categories (PERMANOVA, pseudo-F $=26.3, \mathrm{R}^{2}=0.28, \mathrm{p}<0.001$ ), days after heating (PERMANOVA, pseudo-F $=17.7, \mathrm{R}^{2}=0.18, \mathrm{p}<0.001$ ), and the interaction of MW intensities $\times$ days after heating $($ PERMANOVA, pseudo-F $=14.56$, $\mathrm{R}^{2}=0.15, \mathrm{p}<0.001$ ) on the bacterial community composition (Figure 2 ). Community composition varied along the penetration depth of MW energy (PERMANOVA, pseudo-F $=3.22, \mathrm{R}^{2}=0.03, \mathrm{p}=0.034$, Figure 2 ).

\section{Bacterial Community Richness:}

High MW soil heating intensities significantly reduced bacterial community diversity relative to the low intensity treatments, evidenced by decreasing Shannon richness index (ANOVA; $p<0.001$, Figure 3 ) at T0. This reduction in richness was still detected at T28 (Tukey post-hoc test; $\mathrm{p}<0.0001$ for comparison among low and high intensities at T28 for either penetration depths). Additionally, the combination of MW heating intensity $\times$ days after heating had a significant impact on the community richness (ANOVA; $\mathrm{p}<0.001$; Figure 3). Immediately after heating (T0), high intensity treatment induced a 58\% reduction in richness, on average, regardless of penetration depths.

\section{Phylum- and Genus-Level Responses:}

Bacterial community responses to the combined effect of MW heating intensities and penetration depth were assessed at the phylum and genus levels. Across all samples, Actinobacteria (37.3\%) was the predominant phylum followed by Proteobacteria 
(26.7\%), Gemmatimonadetes (7.9\%), Acidobacteria (7.2\%) and Firmicutes (6.1\%). At 0 - $5 \mathrm{~cm}$ depth, the relative abundance of Proteobacteria significantly increased and Firmicutes decreased with high heating intensities at T0 (ANOVA; $<<0.001$; Figure 4) while Proteobacteria remained dominate, and Firmicutes exhibited recovery at T28. At 5 - $10 \mathrm{~cm}$ depth, Proteobacteria significantly decreased and did not recover to control levels by T28, and Firmicutes increased according to high heating intensities at T0 (ANOVA; $<<0.001$; Figure 4) and remained higher in the community by T28. Actinobacteria showed significantly higher relative abundance by T28 than at T0 (ANOVA; $p<0.001$; Figure 4).

Of the 10 most abundant genera across all samples, at $0-5 \mathrm{~cm}$ depth, the relative abundance of the Bacillus and an unclassified Gaiellaceae significantly increased with high heating intensity (ANOVA; $<<0.001$; Figure 4) at T0 and they remained relatively higher in the community by T28. While the relative abundance of Kaistobacter, Micromonosporaceae, TM7-1, Xanthomonadaceae was significantly higher at T28 than at T0. At 5-10 cm depth, the relative abundance of the Bacillus, Gaiellaceae and Kaistobacter significantly increased with high heating intensities while the relative abundance of the Micromonosporaceae, Rhodospirillaceae, Myxococcales and Solirubrobacterales significantly decreased at T0 (ANOVA; $\mathrm{p}<0.001$; Figure 4). Micromonosporaceae, TM7-1 and Bacillus exhibited recovery at T28 (Figure 4, top right panel).

\section{Taxonomic and Functional Gene Abundances:}

This article is protected by copyright. All rights reserved. 
The average abundance of 16S rRNA bacterial gene for the untreated control soil was $10^{10} \pm 0.42$ gene copies $\mathrm{g}^{-1}$ soil. Overall, during the experiment, no significant difference was detected in total 16S rRNA abundance in any of the studied factors (Tukey posthoc test; $\mathrm{p}>$ 0.05; Figure 5D). Similarly, MW soil treatments had no detectable effect on amoA gene abundances at any time point (Figure 5). The total AOB amoA abundance ranged between $10^{7.7} \pm 0.28-10^{7.9} \pm 0.38$ gene copies $\mathrm{g}^{-1}$ soil (Figure $5 \mathrm{~A}$ ), while the total AOA amoA abundance ranged between $10^{6.4} \pm 0.43-10^{7} \pm 0.39$ amoA gene copies $\mathrm{g}^{-1}$ soil (Figure 5B). Overall, the AOB were more abundant than AOA (Figure 5C). Also, the AOB:AOA did not significantly change $(\mathrm{p}>0.05)$ in response to MW soil heating intensities (Figure 5C). 


\section{Discussion}

The primary purporse of the MW weed management technology is to reduce the viability of the soil weed seedbank of the herbicide-resistant weeds as an alternative to chemicals in the no-till agricultural system. A MW prototype has designed to deactivate the germination capacity of soil weed seedbank before crop sowing under field conditions. In this case, MW energy penetrates soil up to $8 \mathrm{~cm}$ for weed seedbank control, and after every centimeter downward the intensity of MW energy declines leading to changes in temperature distribution along the penetration depth. This depends on the soil characteristics, dielectric properties of the soil and the soil moisture content. They potentially regulate the MW-soil interactions (Nelson, 1996). The heating intensities and penetration depth of microwave energy into top soil layer decide the fate of the seedbank. We previously observed that the temperature requirement for this task ranged between $75-80^{\circ} \mathrm{C}$ for effective weed seedbank depletion (Brodie et al., 2018). Likewise, soil microorganisms also affect by MW energy along the penetration depth. Understanding the response of soil bacterial communities to this changing temperature intensities is crucial for the maintenance of ecosystem services provided by the soil biota and this information will help in calibrating the heating intensities for different soil conditions and farming prcatices.

Therefore, a major aim of this study was to evaluate the effect of MW soil heating on the soil bacterial communities and on the total abundance of AOB and AOA at two penetration depths. The temperature distribution, achieved through MW energy 
application in the top soil layer has been simulated elsewhere (Brodie, 2016), where it was reported that most of the MW energy attenuation (i.e., conversion of electric field into heat energy) occurred between $0-8 \mathrm{~cm}$ of soil. A similar temperature distribution pattern was found in the microcosm of this study (see, Figure S4 and S5). Generally, when the temperature equilibrium of soil is altered by MW heating, both MW energy diffusion and heat transfer happen, and the majority of MW energy attenuation occurs in the top few centimeters for disinfestation. The temperature distribution of deeper sites (for example, 5 - $10 \mathrm{~cm}$ in this study) depends on heat conduction, and during conduction, heat lost to the atmosphere causes cooler and hotter spots (i.e., inconsistency in soil heating) in the lower penetration depth, as detected in the microcosm of the present study (Figure S4). Relevant to this, Casu et al. (2018) presented a 1-D transmission-line model to predict the feasibility of MW soil treatment for disinfestation purposes in raised-bed agricultural systems. Their simulation represented the time required to attain the lethal temperature and its retention into the soil against various penetration depths to eradicate pathogens. They computed that moist soil requires lesser time to achieve the target temperature for up to $15 \mathrm{~cm}$ depth on the raised bed than dry soil, and the temperature differed considerably along with penetration depth. Therefore, the temperature variability along the penetration depth would potentially alter the disinfestation process, as evident by the present study. 
Based on the PCoA of Bray-Curtis distance, we categorised different MW heating durations into two groups: the low heating intensities, where soil exposed to $30 \mathrm{~s}$ did not induce a discernible effect on the bacterial communities and clustered closely to untreated control soil; and the high heating intensities, where 60 and 90 s treatments induced a significant divergence in bacterial communities, and clustered closely overtime. The observed patterns likely depended on temperature distribution, peak temperature retention into soil and bacterial differential recolonization patterns following heating (Neary et al., 1999).

Microbial mortality is caused by the hyperthermic conditions induced by MW energy application into soil (Vela et al., 1976; Vela \& Wu, 1979), and, during recovery, community change occurs, which can then decide the fate of survival taxa and their role in shaping the overall bacterial communities’ structure (Voort et al., 2016). In this study, the high heating intensities $\left(65-78^{\circ} \mathrm{C}\right)$ resulted in a divergence in the bacterial communities' composition (Figure 2). This is in agreement with findings of Russell (2003), where high temperature treatment $\left(50-60{ }^{\circ} \mathrm{C}\right)$ dramatically altered the structure and physiological properties of the bacterial communities, resulting in a changed community structure. In contrast, PietikaÈinen et al. (2000) reported that heating soils to $45-160{ }^{\circ} \mathrm{C}$ did not reduce the bacterial abundances in soils. Therefore, based on this, it can be inferred that complete soil sterilization is somehow hard to occur.

Based on the bacterial richness, the communities disturbed with high intensity MW treatment did not recover to their pre-heating richness within the period studied (28 
days; Figure 3). This suggests that the four weeks for bacterial recolonization following heat disturbance of $75-80^{\circ} \mathrm{C}$, appeared to be an insufficient duration for bacterial recovery. A similar pattern was observed in a recent study where the soil bacterial community declined with a 90 s MW treatment (800 W; $2.45 \mathrm{GHz})$, and subsequently underwent a successional shift, approaching community recovery by 29 days after soil heating (Jurburg et al., 2017). In contrast, Voort et al. (2016) found higher community richness with $80^{\circ} \mathrm{C}$ soil heating treatment for $1 \mathrm{~h}$ and argued that this was in agreement with the intermediate disturbance hypothesis (Connell, 1978). According to this hypothesis, species exhibit a trade-off between their ability to compete for survival/regrowth on available resources and their capacity to withstand a certain disturbance (Connell, 1978). In this study, the relative abundance of heatresistant Firmicutes increased and heat-sensitive Proteobacteria decreased with high intensity MW soil treatment at T28 (see Figure 4, right below panel), which potentially exhibits a trade-off between species in response to MW soil heating. Our results show that bacterial diversity declined significantly at lower penetration depth of MW energy into the microcosms (Figure 3). While the lower soil depth should be classified as a moderate heating zone (Figure S4), based on temperature distribution, because MW energy loses its intensity with increasing penetration depth (Nelson, 1996). Therefore, the reduction in community diversity at lower depth (5 $10 \mathrm{~cm}$ ) is probably linked to the reflection of MW energy from the working surface beneath the samples. Thus, the reabsorption of this reflected energy might have changed the soil temperature distribution at lower depths resulting in higher bacterial 
communities' mortality. This phenomenon is highly complex and needs sound simulation modelling for assessment but can be visualized in the cross-sectional thermal image of the microcosm (Figure S3).

Figure 4 depicts that, at T0 the relative abundance of Proteobacteria decreased and Firmicutes increased significantly according to high MW heating intensities while at T28 the TM-7, Firmicutes and Actinobacteria exhibited recovery in response to high heating intensities. In general, the immediate negative impact of soil heating on bacterial communities is mortality (O'Brien et al., 2018), which is evident with a relative abundance of heat-sensitive (e.g., Proteobacteria) to heat-tolerant (e.g., Firmicutes) bacterial taxa in this study. A similar community shift trend has been detected in a recent microcosm study in response to soil heating at up to $65^{\circ} \mathrm{C}$ (Jurburg et al., 2017). In our study, the relative abundance of Actinobacteria, which have previously been identified as being moisture-dependent in another microcosm experiment (Jacquiod et al., 2013), increased with respect to days after heating. We did not observe a decrease in a relative abundance of this phylum with the high intensity MW soil treatments at T0, indicating that they survived the transient heating disturbance.

In our soils, Proteobacteria was the second most abundant phylum. Within this phylum, Beta-proteobacteria have been reported to resist MW heating durations of over 180 s (Nunes et al., 2018), which is in accordance with our findings. 
In this study, the relative abundance of the gram-positive spore-forming genus Micromonosporaceae increased with the high heating intensities of MW soil treatments at lower depths in the microcosm. The heat-induced activation of this genus at $70{ }^{\circ} \mathrm{C}$ has been reported previously (Hoskisson et al., 2000). In addition, Suarez et al. (1980) reported that the dormant spores of Micromonospora were resistant to high temperature exposures $\left(75-90^{\circ} \mathrm{C}\right)$. Micromonospora species have also been reported to mediate crop protection by producing anti-fungal and antimicrobial compounds (Hirsch \& Valdés, 2010), and help in promoting nitrogen-fixing symbioses, root nodulation and phytohormones formation (Solans et al., 2006) and carbon decomposition (Yeager et al., 2017). The favorable response of this genus to heating treatments may explain the reason for a good growth of crops after MW soil treatment for up to two cropping seasons, as reported by Khan et al. (2019). At T28, the relative abundance of Kaistobacter increased significantly. This genus has been known to play an important role in the carbon and nitrogen cycles (Rampelotto et al., 2013). Overall, the high heating intensities $\left(65-78{ }^{\circ} \mathrm{C}\right)$ appeared to reshape the bacterial communities, and the bacterial community's richness did not recover to its pre-heating conditions within the time studied (i.e., four weeks). Further, a less diverse community may be functionally altered (Boynton \& Greig, 2016), and its ability to regulate key soil nutrient processes may be impacted, as soil functionality depends on the soil bacterial community composition (Wagg et al., 2014). 
We did not detect a negative impact of MW soil heating on the ammonia oxidisers over the period studied (28 days; Figure 5). These results supported our hypothesis that ammonia oxidisers are resistant to MW energy, which was initially argued by Vela et al. (1976). They reported that nitrifying bacteria are resistant to at least 40,000 $\mathrm{J} \mathrm{cm}^{-2}$ of MW energy applied to the soil surface. In this study, the maximum applied energy was 2,500 $\mathrm{J} \mathrm{cm}^{-2}$ associated to high intensities MW treatment, as measured by a simulation modelling according to Brodie (2016). Moreover, Ferriss (1984) found that prokaryptes were resistant to MW soil treatment and concluded that soil moisture and MW soil treatment time, which directly relates to the temperature increase, decide the fate of soil microorganisms.

In contrast to our heating method, soil steaming with the temperature gradient of about $80-100{ }^{\circ} \mathrm{C}$ for 10 minutes induced a 10 -fold reduction in the population of AOB in an organic farming soil (Roux-Michollet et al., 2008). In the present study the peak temperature exposure was less than 2 minutes. The difference in response of ammonia oxidizers to MW and steam treatment could be explained through changes in the heat transfer mechanism associated with both soil disinfestation strategies. A similar range of ammonia oxidisers $\left(10^{4}-10^{5}\right.$ amoA gene copies $\mathrm{g}^{-1}$ soil $)$ as those found in our study has been reported in the Southern Australian soils regardless of the management practices (Jenkins et al., 2016).

In this study, the survival of ammonia oxidisers could be explained by a number of factors: (1) variation in microbial distribution into the soil matrix (soil type, soil moisture, soil pH and agricultural stratergies); (2) specific mass and volume of seeds 
(much higher than microbes); and (3) uneven MW energy distribution into soil causes hot and cold spots. Spatial distribution of ammonia oxidisers into soil particles, and preferential localization, can help protect them from extreme conditions. The resistance of soil bacteria and fungi to MW based soil heating is reported in numerous classical studies (Vela \& Wyss, 1965; Vela et al., 1976; Vela \& Wu, 1979; Van Wambeke et al., 1983), and they concluded that both soil heterogeneity and inconsistency of MW heating may have supported the survival of microorganisms.

Overall, this study highlights that high heating intensities $\left(65-78{ }^{\circ} \mathrm{C}\right)$, which are proposed for weed seedbanks depletion, have a strong impact on the bacterial community composition. Four weeks appeared to an insufficient duration for community recovery, following soil heating to $75-80^{\circ} \mathrm{C}$, and a longer monitoring of microbial community recovery following MW weed disinfestation is needed in order to develop appropriate management practices that preserve the long-term functionality of soil biota. We also did not observe the recovery of community richness during the four weeks of study, and further research must also tease apart whether recovery would eventually happen from the remaining microbial seedbank or via immigration of microbes from the surrounding area. At present, the impact of MW soil heating on soil fertility has been monitored for three cropping seasons (Khan et al., 2019). Further long-term monitoring will reveal of whether there are long-term consequences to its application on the soil biota.

\section{Conclusions}


Our study shows that high heating MW intensities, which are proposed for weed management, have a strong effect on the bacterial community composition. The heatresistant bacterial group survived those high heating intensities and remained dominated in the community until T28. Four weeks appeared to be an insufficient duration for community recovery following soil heating at $75-80^{\circ} \mathrm{C}$. This suggests that a longer temporal investigation after MW soil heating is needed to standardize the bacterial community recovery of different cropping systems. In addition, we did not detect any discernible effect of high temperature on the total abundance of ammonia oxidizers. Overall, our study highlights that MW soil treatment can potentially be applied for weed control without significantly damaging the biologically important taxa, but further research is needed to determine how often it may be reapplied, and whether there are long-term consequences to its application on the soil biota.

\section{Acknowledgements}

This research work was executed with generous support of the Agrifutures Australia [Project: PRJ-008765]. We thank to Dr. Rui Liu, Dr. Hangwei Hu and Dr. Ravneet Jhajj (The University of Melbourne, Australia) for experimental technical support in the laboratory. We also thank to Humayun Kabir, PhD candidate the University of Melbourne, for soil sampling, handling and processing in the laboratory. The authors declare no conflict of interest.

\section{Data Availability Statement}

The data will not be shared in order to maintain ethical standards.

This article is protected by copyright. All rights reserved. 


\section{References}

Australian Bureau of Meteorology - Climate data online. Canberra, ACT, Australia: Australian Bureau of Meteorology. Retrieved from http://www.bom.gov.au/climate/data.

Banik, S., Bandyopadhyay, S. \& Ganguly, S. 2003. Bioeffects of microwave-a brief review. Bioresource technology, 87, 155-159.

Banning, N.C., Maccarone, L.D., Fisk, L.M. \& Murphy, D.V. 2015. Ammoniaoxidising bacteria not archaea dominate nitrification activity in semi-arid agricultural soil. Scientific Reports, 5, 11146.

Berendsen, R.L., Pieterse, C.M. \& Bakker, P.A. 2012. The rhizosphere microbiome and plant health. Trends Plant Sci, 17, 478-486.

Boynton, P.J. \& Greig, D. 2016. Species richness influences wine ecosystem function through a dominant species. Fungal ecology, 22, 61-72.

Brodie, G. 2016. Derivation of a cropping system transfer function for weed management: Part 2. Microwave weed management. Global Joural of Agricultural Innovation, Research \& Development, 3, 1-9.

Brodie, G. 2018. The Use of Physics in Weed Control. In: Non-Chemical Weed Control, pp. 33-59. Elsevier.

Brodie, G., Harris, G., Pasma, L., Travers, A., Leyson, D., Lancaster, C. \& Woodworth, J. 2009. Microwave Soil Heating for Controlling Ryegrass Seed Germination. Transactions of the ASABE, 52, 295-302.

Brodie, G., Khan, J., Gupta, D., Foletta, S. \& Bootes, N. 2017. Microwave Weed and Soil Treatment in Agricultural Systems. pp. 9-17. AMPERE Newsletter: Association for Microwave Power in Europe for Research and Education.

Brodie, G., Khan, M.J., Gupta, D. \& Foletta, S. 2018. Microwave Weed and Soil Treatment in Agricultural Systems. Global Journal of Agricultural Innovation, Research \& Development, 5, 1-14.

Caporaso, J.G., Kuczynski, J., Stombaugh, J., Bittinger, K., Bushman, F.D., Costello, E.K., Fierer, N., Pena, A.G., Goodrich, J.K. \& Gordon, J.I. 2010. QIIME allows analysis of high-throughput community sequencing data. Nature methods, 7, 335-336.

Casu, S., Fanti, A., Lodi, M.B., Spanu, M., Desogus, F. \& Mazzarella, G. 2018. Numerical Estimation of Agricultural Raised Bed Microwave Disinfection. Radio Science, 53, 1176-1186. 
Connell, J.H. 1978. Diversity in tropical rain forests and coral reefs. Science, 199, 1302-1310.

Cozma, P., Apostol, L.C., Hlihor, R.M., Simion, I.M. \& Gavrilescu, M. 2017.

Overview of human health hazards posed by pesticides in plant products. In: $2017 \mathrm{E}$ Health and Bioengineering Conference (EHB), pp. 293-296. IEEE.

DeSantis, T.Z., Hugenholtz, P., Larsen, N., Rojas, M., Brodie, E.L., Keller, K., Huber, T., Dalevi, D., Hu, P. \& Andersen, G.L. 2006. Greengenes, a chimera-checked 16S rRNA gene database and workbench compatible with ARB. Applied and environmental microbiology, 72, 5069-5072.

Diprose, M., Benson, F. \& Willis, A. 1984. The effect of externally applied electrostatic fields, microwave radiation and electric currents on plants and other organisms, with special reference to weed control. The Botanical Review, 50,171223.

Edgar, R.C. 2010. Search and clustering orders of magnitude faster than BLAST. Bioinformatics, 26, 2460-2461.

Edgar, R.C., Haas, B.J., Clemente, J.C., Quince, C. \& Knight, R. 2011. UCHIME improves sensitivity and speed of chimera detection. Bioinformatics, 27, 2194-2200.

Ferriss, R. 1984. Effects of microwave oven treatment on microorganisms in soil. Phytopathology, 74, 121-126.

Fierer, N. 2017. Embracing the unknown: disentangling the complexities of the soil microbiome. Nature Reviews Microbiology, 15, 579.

Fischer, R. \& Connor, D. 2018. Issues for cropping and agricultural science in the next 20 years. Field Crops Research, 222, 121-142.

Francis, C.A., Roberts, K.J., Beman, J.M., Santoro, A.E. \& Oakley, B.B. 2005. Ubiquity and diversity of ammonia-oxidizing archaea in water columns and sediments of the ocean. Procc. of the National Academy of Sciences of the U. S. A., 102, 1468314688.

Fritschi, L., McLaughlin, J., Sergi, C., Calaf, G., Le Curieux, F., Forastiere, F., Kromhout, H., Egeghy, P., Jahnke, G. \& Jameson, C. 2015. Carcinogenicity of tetrachlorvinphos, parathion, malathion, diazinon, and glyphosate. Red, 114.

Glass, D.W., Johnson, D.W., Blank, R.R. \& Miller, W.W. 2008. Factors affecting mineral nitrogen transformations by soil heating: A laboratory-simulated fire study. Soil Science, 173, 387-400.

Heap, I. 2016. International Survey of Herbicide Resistant Weeds. 
Hirsch, A.M. \& Valdés, M. 2010. Micromonospora: An important microbe for biomedicine and potentially for biocontrol and biofuels. Soil Biology and Biochemistry, 42, 536-542.

Hoskisson, P., Hobbs, G. \& Sharples, G. 2000. Response of Micromonospora echinospora (NCIMB 12744) spores to heat treatment with evidence of a heat activation phenomenon. Letters in Applied Microbiology, 30, 114-117.

Isbell, R. 2016. The Australian soil classification. CSIRO publishing: Melbourne.

Jacquiod, S., Franqueville, L., Cécillon, S., Vogel, T.M. \& Simonet, P. 2013. Soil bacterial community shifts after chitin enrichment: an integrative metagenomic approach. PLoS One, 8, 1-13.

Jenkins, S.N., Murphy, D.V., Waite, I.S., Rushton, S.P. \& O’Donnell, A.G. 2016. Ancient landscapes and the relationship with microbial nitrification. Scientific Reports, 6, 30733.

Jurburg, S.D., Nunes, I., Stegen, J.C., Le Roux, X., Priemé, A., Sørensen, S.J. \& Salles, J.F. 2017. Autogenic succession and deterministic recovery following disturbance in soil bacterial communities. Scientific Reports, 7, 1-11.

Khan, M.J., Brodie, G. \& Gupta, D. 2017. The Effect of Microwave Soil Treatment on Rice Production under Field Conditions. Transactions of the ASABE, 60, 517-525.

Khan, M.J., Brodie, G.I., Gupta, D. \& Foletta, S. 2018. Microwave Soil Treatment Improves Weed Management in Australian Dryland Wheat. Transactions of the $A S A B E, \mathbf{6 1}, 671-680$.

Khan, M.J., Brodie, G.I., Gupta, D. \& He, J. 2019. Microwave Soil Treatment Increases Soil Nitrogen Supply for Sustained Wheat Productivity. Transactions of the ASABE, 62, 355-362.

Leininger, S., Urich, T., Schloter, M., Schwark, L., Qi, J., Nicol, G.W., Prosser, J.I., Schuster, S. \& Schleper, C. 2006. Archaea predominate among ammonia-oxidizing prokaryotes in soils. Nature, 442, 806-809.

Lu, Y., Lu, S., Horton, R. \& Ren, T. 2014. An empirical model for estimating soil thermal conductivity from texture, water content, and bulk density. Soil Science Society of America Journal, 78, 1859-1868.

McMurdie, P.J. \& Holmes, S. 2013. phyloseq: an R package for reproducible interactive analysis and graphics of microbiome census data. PLoS One, 8, e61217.

Metaxas, A.a. \& Meredith, R.J. 1983. Industrial microwave heating. IET. 
Neary, D.G., Klopatek, C.C., DeBano, L.F. \& Ffolliott, P.F. 1999. Fire effects on belowground sustainability: a review and synthesis. Forest ecology and management, 122, 51-71.

Nelson, S. 1996. A review and assessment of microwave energy for soil treatment to control pests. Transactions of the ASAE, 39, 281-289.

Nunes, I., Jurburg, S., Jacquiod, S., Brejnrod, A., Salles, J.F., Priemé, A. \& Sørensen, S.J. 2018. Soil bacteria show different tolerance ranges to an unprecedented disturbance. Biology and Fertility of Soils, 54, 189-202.

O'Brien, P.L., DeSutter, T.M., Casey, F.X., Khan, E. \& Wick, A.F. 2018. Thermal remediation alters soil properties-a review. Journal of Environmental Management, 206, 826-835.

Oksanen, J., Kindt, R., Legendre, P., O’Hara, B., Simpson, G.L., Solymos, P., Stevens, M.H.H. \& Wagner, H. 2008. The vegan package. Community ecology package.[http://r-forge. r-project. org/projects/vegan/].

PietikaÈinen, J., Hiukka, R. \& Fritze, H. 2000. Does short-term heating of forest humus change its properties as a substrate for microbes? Soil Biology and Biochemistry, 32, 277-288.

Pretty, J. \& Bharucha, Z.P. 2014. Sustainable intensification in agricultural systems. Annals of Botany, 114, 1571-1596.

Rampelotto, P.H., de Siqueira Ferreira, A., Barboza, A.D.M. \& Roesch, L.F.W. 2013. Changes in diversity, abundance, and structure of soil bacterial communities in Brazilian Savanna under different land use systems. Microbial ecology, 66, 593-607.

Rotthauwe, J.-H., Witzel, K.-P. \& Liesack, W. 1997. The ammonia monooxygenase structural gene amoA as a functional marker: molecular fine-scale analysis of natural ammonia-oxidizing populations. Applied Environmental Microbiology, 63, 47044712.

Roux-Michollet, D., Czarnes, S., Adam, B., Berry, D., Commeaux, C., Guillaumaud, N., Le Roux, X. \& Clays-Josserand, A. 2008. Effects of steam disinfestation on community structure, abundance and activity of heterotrophic, denitrifying and nitrifying bacteria in an organic farming soil. Soil Biology and Biochemistry, 40, 1836-1845.

Russell, A. 2003. Lethal effects of heat on bacterial physiology and structure. Science progress, 86, 115-137. 
Sabry, A., Allam, A., Abdel-Rahman, A.B. \& El-Ansary, D. 2018. A Novel Microwave Applicator for Sandy Soil Disinfection. In: 2018 Progress in Electromagnetics Research Symposium (PIERS-Toyama), pp. 636-641. IEEE.

Sánchez-Marañón, M., Miralles, I., Aguirre-Garrido, J.F., Anguita-Maeso, M., Millán, V., Ortega, R., García-Salcedo, J.A., Martínez-Abarca, F. \& Soriano, M. 2017. Changes in the soil bacterial community along a pedogenic gradient. Scientific Reports, 7, 1-11.

Sartorato, I., Zanin, G., Baldoin, C. \& De Zanche, C. 2006. Observations on the potential of microwaves for weed control. Weed Research, 46, 1-9.

Solans, M., Vobis, G., Cassán, F., Masciarelli, O., Luna, V. \& Wall, L. 2006.

Producción de Fitohormonas por Rhizoactinomycetes; Posibles Efectos Sobre la Simbiosis. Discaria trinervis-Frankia. XXVI Reunión de la Asociatión Argentina de Fisilogía Vegetal. Book of abstracts, PII, 74.

Suarez, J.E., Barbes, C. \& Hardisson, C. 1980. Germination of spores of Micromonospora chalcea: physiological and biochemical changes. Microbiology, 121, 159-167.

Suzuki, M.T., Taylor, L.T. \& DeLong, E.F. 2000. Quantitative analysis of smallsubunit rRNA genes in mixed microbial populations via 5'-nuclease assays. Applied and environmental microbiology, 66, 4605-4614.

Team, R., C. . 2014. R: a language and environment for statistical computing. R foundation for Statistical Computing, Vienna, Austria., http:/www.R-project.org/

Van Wambeke, E., Wijsmans, J. \& d'Hertefelt, P. 1983. Possibilities in microwave application for growing substrate disinfestation. In: II International Symposium on Soil Disinfestation 152, pp. 209-218.

Vela, G. \& Wu, J. 1979. Mechanism of lethal action of 2,450-MHz radiation on microorganisms. Applied and environmental microbiology, 37, 550-553.

Vela, G., Wu, J. \& Smith, D. 1976. Effect of $2450 \mathrm{MHz}$ Microwave Radiation on Some Soil Microorganisms in situ. . Soil Science, 121, 44-51.

Vela, G.R. \& Wyss, O. 1965. Radiation resistance of soil Azotobacter. Journal of bacteriology, 89, 1280-1285.

Voort, M., Kempenaar, M., van Driel, M., Raaijmakers, J.M. \& Mendes, R. 2016. Impact of soil heat on reassembly of bacterial communities in the rhizosphere microbiome and plant disease suppression. Ecology letters, 19, 375-382. 
Wagg, C., Bender, S.F., Widmer, F. \& van der Heijden, M.G. 2014. Soil biodiversity and soil community composition determine ecosystem multifunctionality. Proceedings of the National Academy of Sciences, 111, 5266-5270.

Yeager, C.M., Dunbar, J., Hesse, C.N., Daligault, H. \& Kuske, C.R. 2017.

Polysaccharide degradation capability of Actinomycetales soil isolates from a semiarid grassland of the Colorado Plateau. Applied and environmental microbiology, AEM. 03020-03016.

Yu, Y., Lee, C., Kim, J. \& Hwang, S. 2005. Group-specific primer and probe sets to detect methanogenic communities using quantitative real-time polymerase chain reaction. Biotechnology and bioengineering, 89, 670-679.

Zagal, E. 1989. Effects of microwave radiation on carbon and nitrogen mineralization in soil. Soil Biology and Biochemistry, 21, 603-605.

Zhang, J., Kobert, K., Flouri, T. \& Stamatakis, A. 2013. PEAR: a fast and accurate Illumina Paired-End reAd mergeR. Bioinformatics, 30, 614-620.

This article is protected by copyright. All rights reserved. 


\section{FIGURE CAPTIONS}

Figure 1 Infrared thermal images of microcosm treated through microwave energy under horn antenna of microwave weed killer depicting the gradual increase in soil temperature. Note: the untreated control soil ( 0 s; A), 30 s exposure (B), 60 s exposure (C) and 90 s exposure (D). Image was captured within $2-3 \mathrm{~s}$ after microwave soil heating and temperature loss during this time was negligible. The raw images were post-processed in MATLAB for temperature forecasting.

Figure 2 Principle coordinate analyses of Bray-Curtis dissimilarity index-based variation in the community composition with microwave soil heating treatment over two-time points.

Figure 3 Variation in bacterial diversity against microwave soil heating. Shannon richness calculated from the 16S rRNA gene sequence data for the different treatment combinations at two-time points.

Figure 4 Relative abundance of the predominated bacterial taxa and genera that significantly changed over time in response to microwave soil heating intensities.

Figure 5 Influence of microwave soil heating on the total abundance of the AOB (A), AOA (B), AOA:AOB (C) and 16S rRNA bacterial gene (D). The log-transferred gene copies number per gram soil are plotted against the various doses of soil microwave treatment monitored at two times points. 


\section{Figures}
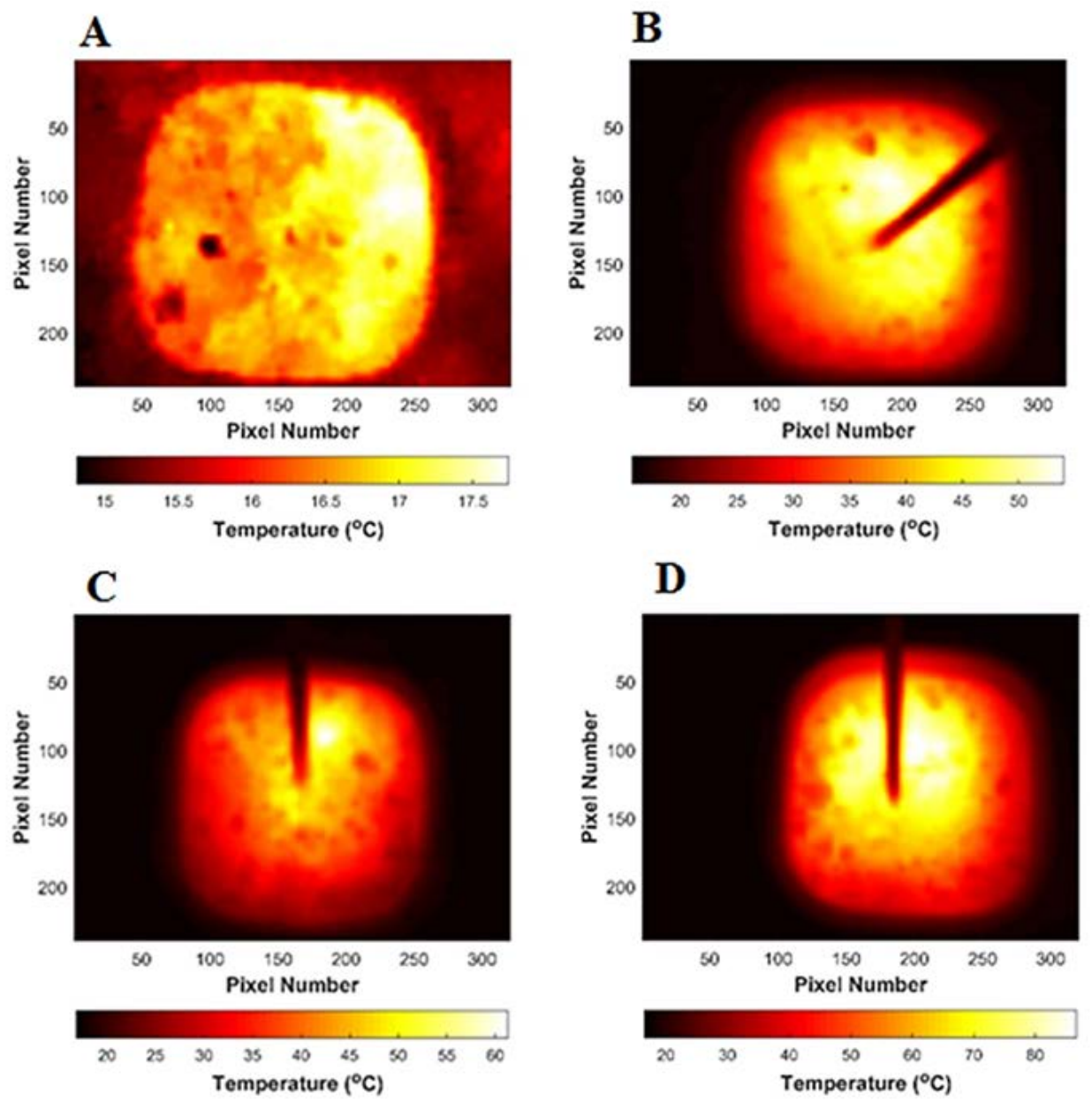

\section{Figure 1}

This article is protected by copyright. All rights reserved. 


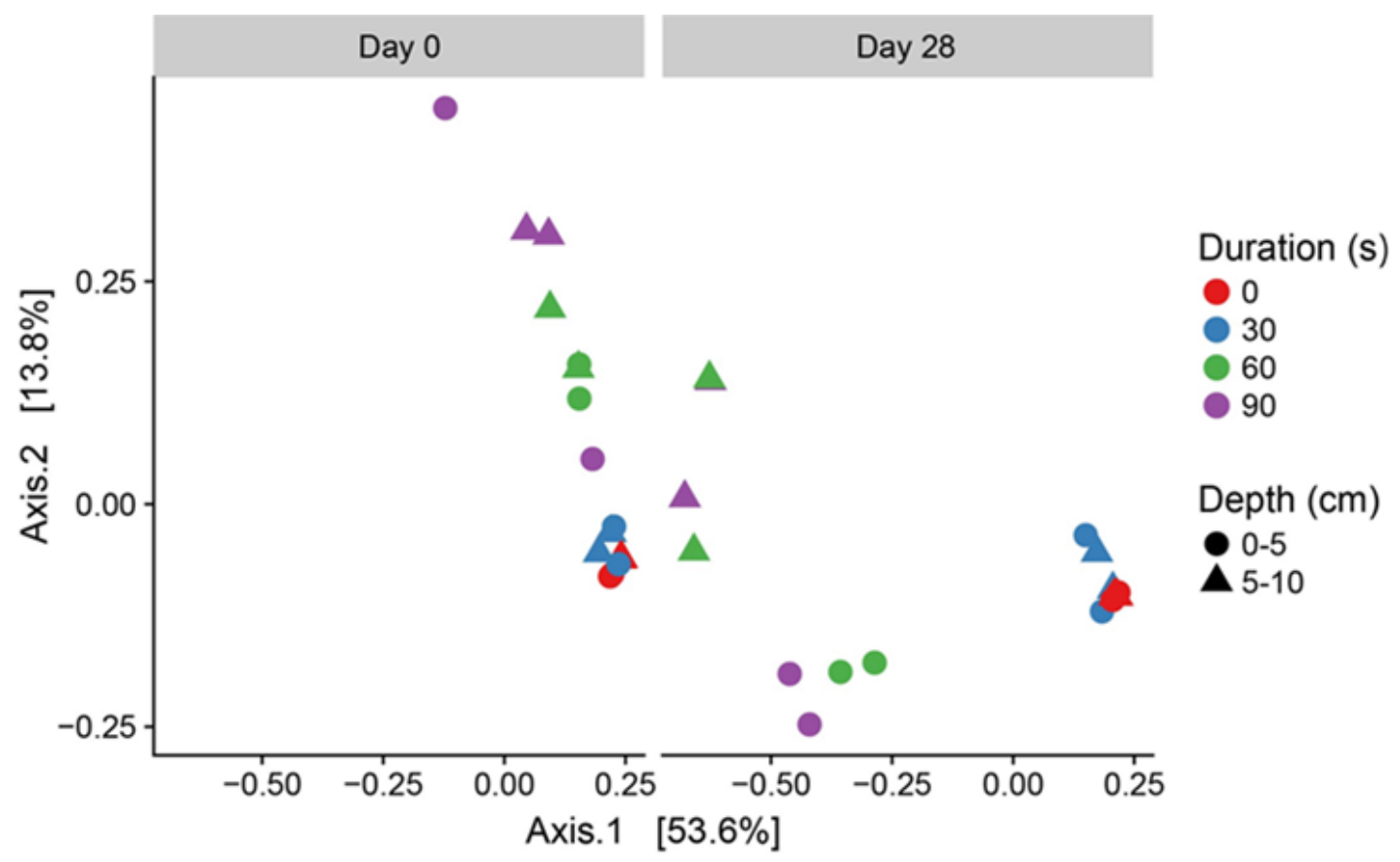

Figure 2

This article is protected by copyright. All rights reserved. 


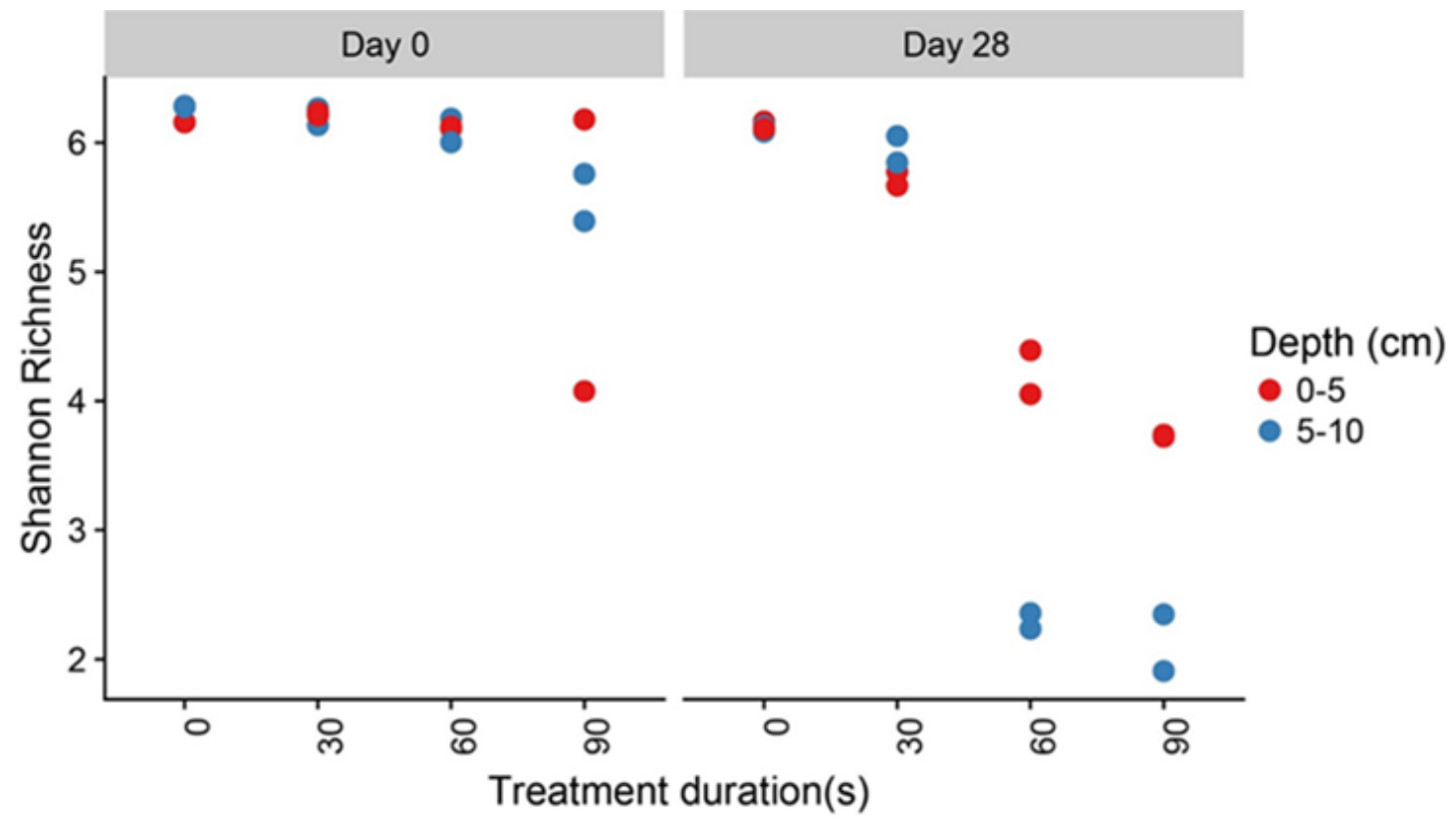

Figure 3

This article is protected by copyright. All rights reserved. 


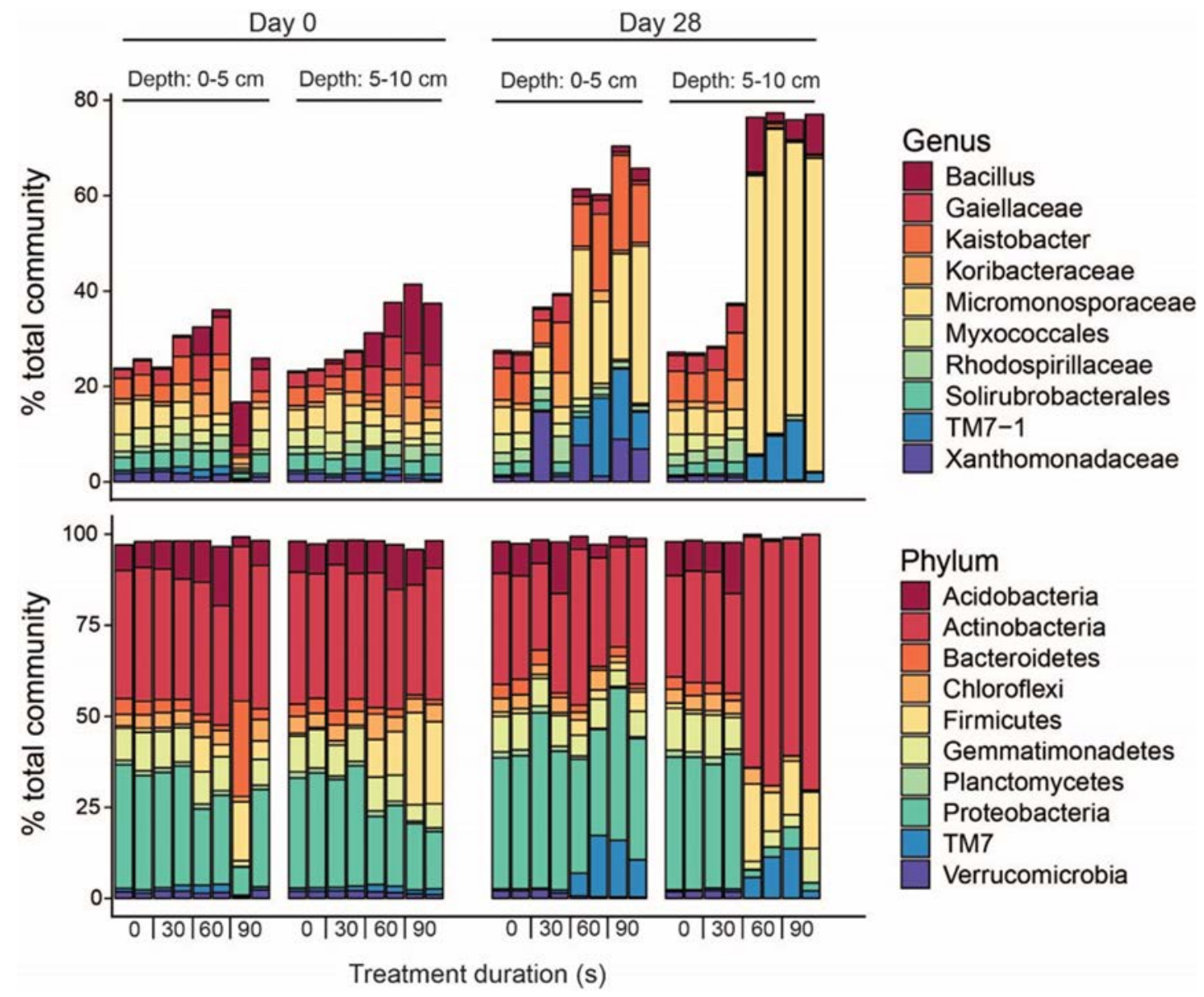

Figure 4

This article is protected by copyright. All rights reserved. 

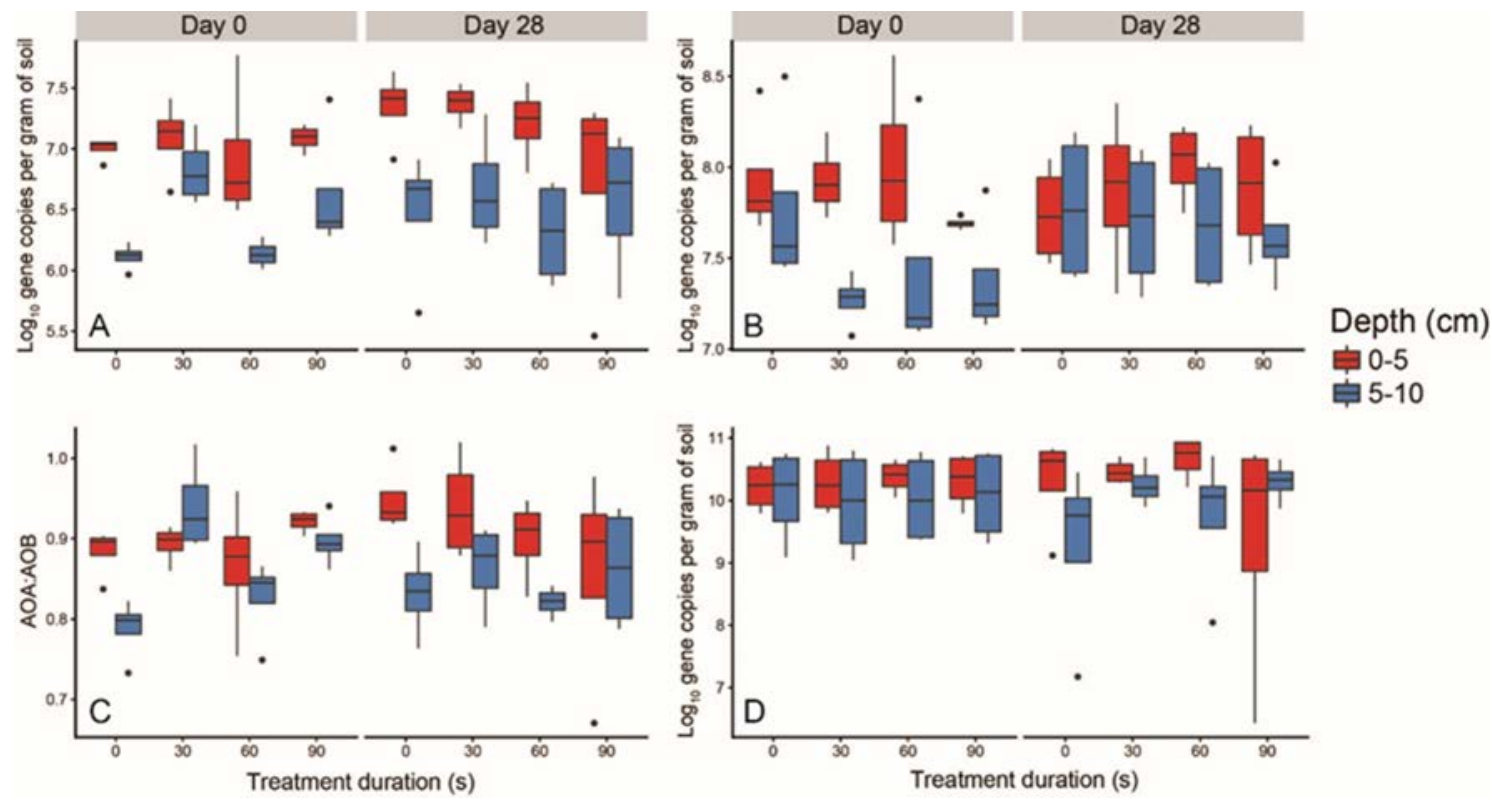

\section{Figure 5}

This article is protected by copyright. All rights reserved. 


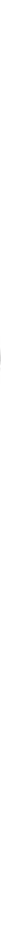




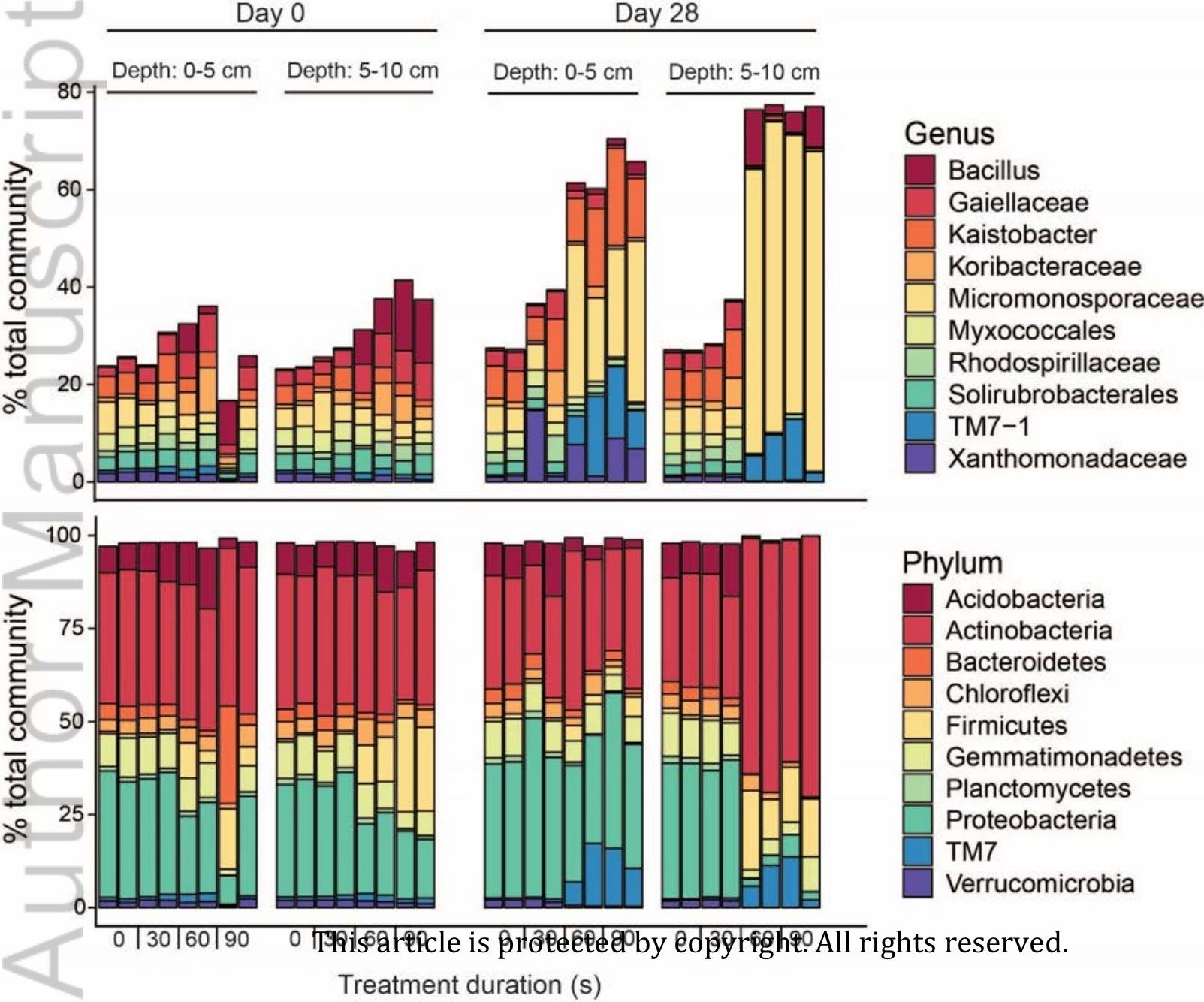




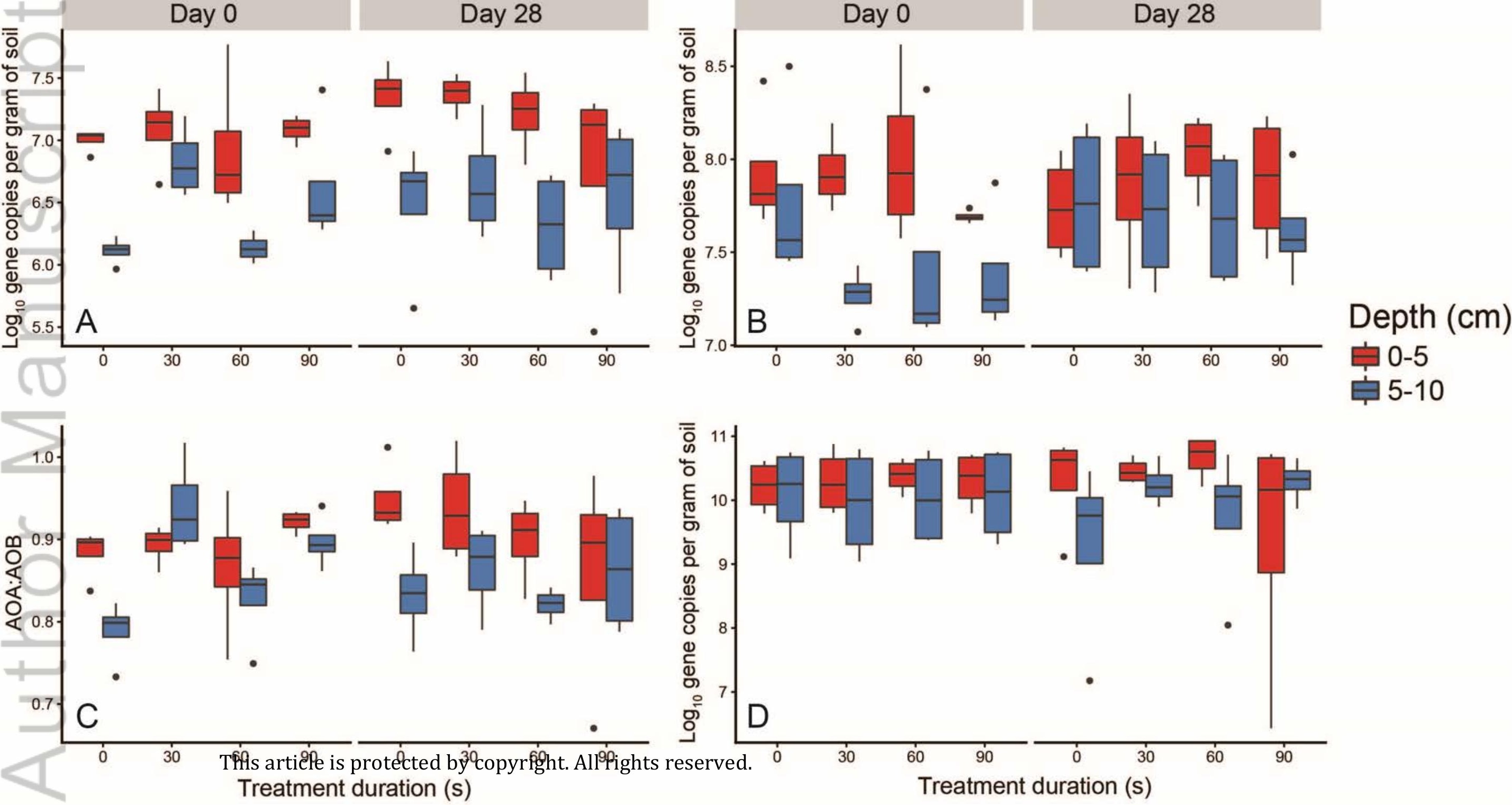




\section{University Library}

\section{- M M N E R VA A gateway to Melbourne's research publications}

Minerva Access is the Institutional Repository of The University of Melbourne

Author/s:

Khan, MJ;Jurburg, SD;He, J;Brodie, G;Gupta, D

Title:

Impact of microwave disinfestation treatments on the bacterial communities of no-till agricultural soils

Date:

2019-08-20

\section{Citation:}

Khan, M. J., Jurburg, S. D., He, J., Brodie, G. \& Gupta, D. (2019). Impact of microwave disinfestation treatments on the bacterial communities of no-till agricultural soils.

EUROPEAN JOURNAL OF SOIL SCIENCE, 71 (6), pp.1006-1017. https://doi.org/10.1111/ ejss. 12867.

Persistent Link:

http://hdl.handle.net/11343/286314 